This is an electronic reprint of the original article. This reprint may differ from the original in pagination and typographic detail.

Author(s): Saarikallio, Suvi

Title: Development and Validation of the Brief Music in Mood Regulation Scale (B-MMR)

Year: $\quad 2012$

Version:

Please cite the original version:

Saarikallio, S. (2012). Development and Validation of the Brief Music in Mood Regulation Scale (B-MMR). Music Perception: An Interdisciplinary Journal, 30(1), $97-$ 105. https://doi.org/10.1525/mp.2012.30.1.97

All material supplied via JYX is protected by copyright and other intellectual property rights, and duplication or sale of all or part of any of the repository collections is not permitted, except that material may be duplicated by you for your research use or educational purposes in electronic or print form. You must obtain permission for any other use. Electronic or print copies may not be offered, whether for sale or otherwise to anyone who is not an authorised user. 


\section{Development and Validation of the Brief Music in Mood Regulation Scale (B-MMR)}

Suvi SaARikallio University of Jyväskylä, Jyväskylä, Finland

MOOD REGULATION HAS BEEN SHOWN TO BE AMONG OF THE most important reasons for musical engagement, but there has been a lack of a concise measurement instrument for this behavior. The current study focused on developing and testing the Brief Music in Mood Regulation scale (BMMR), a 21-item self-report instrument for assessing the use of seven different music-related mood-regulation strategies. Two survey studies $(N=1515$ and $N=526)$ were conducted to first develop and then test and validate the instrument. The newly constructed scale showed adequate internal consistency reliabilities and correlated expectedly with measures of general emotion regulation and musical engagement. As a concise and theoretically coherent measure, the B-MMR may prove to be highly applicable for future surveys and comparative studies.

Received September 20, 2010, accepted January 19, 2012.

Key words: music, emotion, mood regulation, emotion regulation, questionnaire

$\mathrm{M}$ USIC HAS BEEN RECOGNIZED AS AN EFFECTIVE means for regulating mood. For instance, Thayer, Newman, and McClain (1994) found music listening to be second in success at changing a bad mood, raising energy, and reducing tension when compared to 18 other regulatory strategies such as humor or physical exercise. Music has been proposed to serve as a means for self-therapy (DeNora, 1999; Sloboda \& O’Neill, 2001), have beneficial effects on stress reduction (Pelletier, 2004), and enhance mood improvement and coping both in everyday life contexts (e.g., Saarikallio \& Erkkilä, 2007) and in clinical settings (e.g., Kenny \& Faunce, 2004; Särkämö et al., 2008). Recent research has investigated central processes of music-related mood regulation identifying music-related regulatory goals and strategies (Saarikallio \& Erkkilä, 2007; Van Goethem, 2009) as well as various music-related emotion induction mechanisms causing the mood change (e.g., Juslin \& Västfjäll, 2008). Yet, although the use of music as a means for mood regulation is widely recognized, there has been a lack of a compact measurement scale for assessing this behavior. A brief and valid measurement tool would be highly useful for experiments, surveys, and comparative studies.

The ability to manage affective states is considered essential for adaptive human behavior, coping, and emotional intelligence (Gross, 1998; Larsen, 2000; Salovey, Bedell, Detweiler, \& Mayer, 2000). The concept of mood or emotion regulation refers to processes of modifying the occurrence, duration, and intensity of both negative and positive affective states (e.g., Gross, 1998; Larsen, 2000). Moods are typically differentiated from emotions by their longer duration, lower intensity, and lack of specific object. Both of these concepts, however, also share similar components such as subjective feelings, physiological reactions, and behavioral expressions and regulation may focus on any of them (e.g., Gross, 1998; Larsen, 2000). Regulatory behavior can be divided into cognitive versus behavioral strategies (e.g., Catanzaro \& Mearns, 1990; Parkinson, Toterdell, Briner, \& Reynolds, 1996), it may occur at different stages of an emotional process (antecedent-focused versus response-focused regulation, e.g., Gross \& John, 2003), and it may or may not be conscious (e.g., Gross, 1998; Larsen, 2000). Moreover, as a distinction to coping behavior, the concept of mood regulation emphasizes changes in the affective states per se without concerning the stressors and ways to manage them (e.g., Gross, 1998; Larsen, 2000).

The current paper focuses on music as a means for realizing affect-regulatory behavior. Previously, a pioneering measurement scale labeled MMR (Music in Mood Regulation) was developed and tested by Saarikallio (2008). MMR was validated with a sample of adolescents (mean age $=15.01$, age range $=10-20$ ) and is particularly targeted for young people. On basis of a prior theory (Saarikallio \& Erkkilä, 2007) the measurement model of MMR includes a second-order factor, "use of music for mood regulation," which consists of seven subfactors representing the following mood-regulatory strategies: 1) Entertainment, creating nice atmosphere and happy

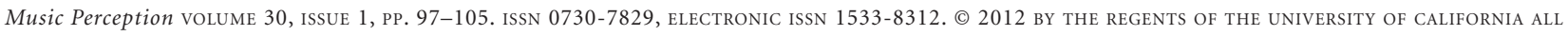
RIGHTS RESERVED. PLEASE DIRECT ALL REQUESTS FOR PERMISSION TO PHOTOCOPY OR REPRODUCE ARTICLE CONTENT THROUGH THE UNIVERSITY OF CALIFORNIA PRESS'S RIGHTS AND PERMISSIONS WEBSITE, HTTP://WWW.UCPRESSJOURNALS.COM/REPRINTINFO.ASP.DOI: 10.1525/MP.2012.30.1.97 
feeling to maintain or enhance current positive mood, 2) Revival, personal renewal, relaxing, and getting new energy from music when stressed or tired, 3) Strong Sensation, inducing and strengthening intense emotional experiences, 4) Diversion, forgetting unwanted thoughts and feelings with the help of pleasant music, 5) Discharge, release of negative emotions through music that expresses these emotions, 6) Mental Work, using music as a framework for mental contemplation and clarification of emotional preoccupations, and finally, 7) Solace, searching for comfort, acceptance, and understanding when feeling sad and troubled.

The MMR scale includes a total of 40 item statements assessing the abovementioned strategies. All statements are answered with a 5-point Likert scale ranging from "Strongly Disagree" to "Strongly Agree." The total score for MMR can be calculated to assess the second-order factor, or the subscales can be used as separate scales. Regarding musical engagement, the scale focuses on self-chosen, voluntary engagement, as opposed to involuntary and random encounters with music, in line with the "uses and gratifications" approach studying individuals as active agents using media for their personal needs (e.g., DeNora, 2001). The musical behavior serving as means for realizing the strategies is in some statements defined broadly with the term music (e.g., "Music helps me to understand different feelings in myself" - Mental Work), while other items refer to the more specific behavior of listening ("When I'm angry with someone, I listen to music that expresses my anger" Discharge). Listening is used in the scale because it has been shown to be typical for young people's mood regulation: it appears as one of the most characteristic musical activities for all regulatory strategies (Saarikallio \& Erkkilä, 2007), and when adolescents who played an instruments were asked to indicate which of eight musical activities changed their mood, 51\% selected "listening alone" (Saarikallio, 2006). Also, since not all people sing or play an instrument, only listening is used in order to keep the scale applicable for all.

The MMR scale focuses on regulation through musical behavior, but shares common ground with general affect regulation theories (Saarikallio \& Erkkilä, 2007). Regarding the distinction of mood and emotion, MMR is not restricted to, but focuses on mood-like undifferentiated states in comparison to specific emotional reactions. It focuses on the changes in mood per se, remaining neutral regarding stressors or other causes of the original mood as well as regarding mood induction mechanisms (such as episodic memory or emotional contagion, see Juslin \& Västfjäll, 2008). Regarding positive and negative states, MMR includes both the element of maintaining and enhancing positive moods (e.g., Entertainment, Strong Sensation) as well as several ways of dealing with stress and negative emotion (e.g., Diversion, Discharge, Solace). Regarding emotional process or the evolvement of affective reactions over time, strategies such as Entertainment and Strong Sensation focus on the early stages of situation modification and emotion induction. Also, Mental Work, Diversion, Revival, and Solace focus on changing the experience before affective response tendencies are fully generated, while Discharge in particular is a responsefocused strategy focusing on modifying the behavioral expression of an already activated affective state (Saarikallio, 2011). Regarding behavioral versus cognitive orientation, there is no clear distinction between thinking instead of acting, but many MMR items are characterized with a reference to music as a promoter of the mental processing of the experience (e.g., "When everything feels bad, music understands and comforts me" - Solace).

The aim of the current study was to further develop the MMR scale in order to construct a shorter and more easily administrable version of the instrument. Furthermore, the reliability and validity of the brief version were tested. Validity was assessed through comparisons with both musical engagement and general emotion regulation. Previous research has shown that highly engaged music users - who spend a great amount of time on music listening and value the personal choice of music they hear - are also more likely to use music for emotional purposes (Greasley \& Lamont, 2011). Thus, MMR was expected to correlate with the amount of music listening and the importance of musical engagement. Emotion Regulation Questionnaire (ERQ) developed by Gross and John (2003) was selected as a measure of general affect regulation tendencies. It consists of two different emotion regulation strategies: Reappraisal (cognitive reinterpretation of emotional experiences) and Suppression (attempts of controlling the expression of an already activated emotion). Reappraisal was considered reflective of the nature of music-related mood regulation because, like all MMR subscales except for Discharge, Reappraisal focuses on regulating emotion at relatively early stages of the response. It also focuses on cognitive processes, as do many items of MMR, and consists of a range of ways of modifying the affective state (increase positive, decrease negative, control emotions, deal with stressful situation), as does MMR. Accordingly, positive correlations between Reappraisal and MMR strategies (except for Discharge) were hypothesized. The other ERQ subscale, Suppression, refers to response-focused regulation, and was thus not expected to correlate 
with MMR. The only response-focused MMR strategy, Discharge, also is not about suppression of emotion but rather about enhanced expression of the experienced emotion and was thus not expected to correlate with Suppression. The only MMR strategy sharing some conceptual similarity to Suppression might be Diversion, as both strategies refer to a tendency of not focusing on the current affective state. Nevertheless, Diversion refers to a relatively early redirection of attention into a pleasant, emotion-irrelevant musical activity causing mood improvement, while Suppression focuses on preventing the expression of an already activated negative emotion while possibly maintaining the negative experience. Therefore, no correlation was also expected between Suppression and Diversion.

\section{Method}

Two survey studies were conducted in order to first develop, then test and validate the brief version of the MMR. Survey data from a previous study (Saarikallio, 2008), in which the original 40-item scale was developed, was first used to construct the brief version. This sample consisted of 1,515 adolescents, 652 boys and 820 girls (43 subjects did not mark gender), with an age range of 10-20 years, and a mean age of 15.01 years. At the time of the original scale development, the 40-item MMR scale was tested through confirmatory factor analysis, with a range of goodness-of-fit indicators indicating an acceptable model fit for the factor structure $(\mathrm{CFI}=.91$; TLI $=.90 ;$ RMSEA $=.05$; and SRMR $=.05)$, (see Saarikallio, 2008). All items with acceptable $R^{2}$ values, factor loadings, error residuals, and cross-loadings were included in the original scale.

In the current analysis the number of variables was further reduced in order to create as brief a version of the measure as possible. Item selection was based on both statistical and conceptual criteria. Regarding the statistical criteria, the goal was to include items with high $R^{2}$ values (i.e., the percentage of the variance of the item explained by its respective subfactor) indicating good effect size for the item, items with low error residuals, and items loading strongly on their presumed subfactor while not loading high on the other subfactors. The $R^{2}$ values, factor loadings, error residuals, and cross-loadings (higher than .30) of all items are listed in Appendix A. All selected items loaded highly on their presumed subfactors. Regarding the cross-loadings, Diversion and Mental Work included items that also loaded on some other subfactors: Diversion items loaded on Revival, Strong Sensation, Mental Work, and
Solace, and Mental Work items loaded on Diversion and Solace. However, since all of these items still had higher loadings on their presumed subfactors, they were accepted for inclusion. After all, some crossloadings were expected since all subfactors measure the same second-order factor of musical mood regulation. No other items showed high cross-loadings.

Since the original set of the 40 items was already based on statistical criteria, none of the original items contained highly problematic statistical properties, but the original scale consisted of a different number of items per each subfactor. Therefore, item selection was supported by conceptual evaluation. That is, the statistical criteria were applied separately for each subfactor so that each factor was allowed to retain only three items, and some items were excluded not due to deficits in statistical properties but due to conceptually repeating another item in the subfactor (e.g., for Strong Sensation, "Music offers me unforgettable moments" was excluded because it somewhat repeated the item: "Music has offered me magnificent experiences"). The combination of statistical and conceptual criteria for item selection ensured inclusion of items with optimal statistical properties while simultaneously retaining comprehensive enough operationalization of the underlying concepts and confirming that each strategy could be reliably measured also through the shortened scale. Thus, based on the abovementioned criteria, the original 40-item MMR scale was reduced into a total of 21 items, three items assessing each sub-scale. The new scale was labeled Brief MMR (B-MMR) and is attached as an appendix (Appendix B).

Next, a second study was conducted in order to test and validate the constructed 21 -item scale with another sample. The total number of participants in this sample was 526, including 357 females and 169 males. The sample consisted of young adults with a mean age of 23.97 years, and although a few older respondents also participated (age range: $19-44$ ), $75 \%$ of the participants were 25 or younger. Thus, the validation of the measure remained focused on young people. The respondents answered both the original 40 -item and the new 21 -item versions of the scale. The alpha reliabilities for both MMR and B-MMR were calculated and compared to each other. To test the external validity of the B-MMR, the questionnaire also included measures of musical engagement and general emotion regulation. Musical engagement was assessed by hours spent on music listening per day and by self-rated importance of music in one's life (answered on a 5-point scale ranging from "not at all important" to "very important"). Both of these aspects have previously been shown to correlate positively with the original MMR (Saarikallio, 2006). The general emotion regulation styles 
were measured through the Emotion Regulation Questionnaire (ERQ) (Gross \& John, 2003), which consists of ten item statements measuring the two emotion regulation strategies, reappraisal, and suppression. The original version of MMR has previously shown to correlate with reappraisal but not with suppression (Saarikallio, 2006, 2008).

\section{Results}

The intercorrelations between the B-MMR subscales were relatively high (ranging from .32 to .77), supporting the second-order factor structure, and were also greatly in line with the inter-correlations of the original MMR sub-scales (Table 1). The Cronbach's alpha coefficients for internal consistency were acceptable for all B-MMR subscales and did not markedly differ from the coefficients of the original sub-scales (Table 2). The alpha coefficients for B-MMR subscales ranged from .73 to .88 , which is relatively high considering that the sub-scales now only consisted of three items each. The internal consistency reliability for the total score of B-MMR was .93 , showing only a minor reduction to the alpha reliability of .96 of the original 40 -item version.

Regarding the correlations of MMR and B-MMR to general emotion regulation and musical engagement,

TABLE 1. Intercorrelations (a) Between the Original MMR subscales and (b) Between the B-MMR subscales.

\begin{tabular}{|c|c|c|c|c|c|c|}
\hline & $\mathrm{E}$ & $\mathrm{R}$ & SS & Div & Dis & MW \\
\hline $\mathrm{R}$ & $.52^{\star \star}$ & & & & & \\
\hline SS & $.47^{\star *}$ & $.63^{* *}$ & & & & \\
\hline Div & $.36^{\star *}$ & $.66^{* *}$ & $.50^{\star *}$ & & & \\
\hline Dis & $.34^{\star *}$ & $.44^{\star *}$ & $.44^{* *}$ & $.34^{* *}$ & & \\
\hline MW & $.39^{\star *}$ & $.67^{\star *}$ & $.73^{\star *}$ & $.61^{* *}$ & $.53^{\star *}$ & \\
\hline$S$ & $.41^{\star *}$ & $.70^{* *}$ & $.65^{\star *}$ & $.67^{\star *}$ & $.55^{\star *}$ & $.80^{*}$ \\
\hline \multicolumn{7}{|c|}{ b) B-MMR } \\
\hline & $\mathrm{E}$ & $\mathrm{R}$ & SS & Div & Dis & MW \\
\hline $\mathrm{R}$ & $.43^{\star *}$ & & & & & \\
\hline SS & $.36^{* *}$ & $.53^{\star *}$ & & & & \\
\hline Div & $.32^{\star *}$ & $.62^{* *}$ & $.45^{\star *}$ & & & \\
\hline Dis & $.26^{* *}$ & $.40^{* *}$ & $.42^{\star *}$ & $.36^{\star \star}$ & & \\
\hline MW & $.32^{\star *}$ & $.58^{\star *}$ & $.64^{\star *}$ & $.61^{\star *}$ & $.50^{\star *}$ & \\
\hline$S$ & $.35^{\star *}$ & $.63^{* *}$ & $.59^{\star *}$ & $.65^{\star *}$ & $.50^{\star *}$ & $.77^{\star \star}$ \\
\hline
\end{tabular}

Note: (abbreviations: $\mathrm{E}$ = entertainment, $\mathrm{R}$ = revival, $\mathrm{SS}=$ strong sensation, Div $=$ diversion, Dis = discharge, $\mathrm{MW}=$ mental work, $\mathrm{S}=$ solace) $; p \leq .01$
TABLE 2. Internal Consistency Reliabilities for the Original MMR and the B-MMR.

\begin{tabular}{|c|c|c|c|}
\hline MMR subscale & & $\begin{array}{c}\text { Cronbach's } \\
\text { alpha }\end{array}$ & $N$ of items \\
\hline \multirow[t]{2}{*}{ Entertainment } & MMR & .81 & 4 \\
\hline & B-MMR & .81 & 3 \\
\hline \multirow[t]{2}{*}{ Revival } & MMR & .87 & 7 \\
\hline & B-MMR & .80 & 3 \\
\hline \multirow[t]{2}{*}{ Strong Sensation } & MMR & .89 & 7 \\
\hline & B-MMR & .81 & 3 \\
\hline \multirow[t]{2}{*}{ Diversion } & MMR & .75 & 5 \\
\hline & B-MMR & .73 & 3 \\
\hline \multirow[t]{2}{*}{ Discharge } & MMR & .89 & 6 \\
\hline & B-MMR & .84 & 3 \\
\hline \multirow[t]{2}{*}{ Mental Work } & MMR & .82 & 5 \\
\hline & B-MMR & .84 & 3 \\
\hline \multirow[t]{2}{*}{ Solace } & MMR & .89 & 6 \\
\hline & B-MMR & .85 & 3 \\
\hline \multirow[t]{2}{*}{ MMR (total score) } & MMR & .96 & 40 \\
\hline & B-MMR & .93 & 21 \\
\hline
\end{tabular}

MMR and B-MMR showed practically identical correlations to the measured variables (Table 3), further indicating that the use of the brief version should not produce a loss or change of information. Moreover, the correlations were in line with the hypotheses drawn from previous research confirming the criterion validity of B-MMR. All MMR strategies, except for Discharge, correlated positively with Reappraisal. As in previous studies (Saarikallio, 2006, 2008), the correlations were relatively low, indicating that even though music-related regulation relates to general emotion regulation, it is a separate construct. As hypothesized, suppression showed no significant positive correlations to any of the MMR strategies, but actually correlated negatively with one of strategies, Strong Sensation. This was not hypothesized but is not surprising considering that the tendency to induce strong emotional experiences is perhaps in contradiction with the tendency of suppressing emotions. Also in line with the hypotheses, all MMR strategies showed significant positive correlations to an increased musical engagement measured by the hours of daily listening and the self-rated importance of music in life. The importance of music was most strongly related to the use of music for Revival, Strong Sensation, Mental Work, and Solace, whereas the two strategies with highest correlations to 


\begin{tabular}{|c|c|c|c|c|}
\hline \multirow[t]{2}{*}{ MMR subscale } & \multicolumn{2}{|c|}{ Emotion regulation } & \multicolumn{2}{|c|}{ Musical engagement } \\
\hline & Reappraisal & Suppression & Importance & Listening \\
\hline \multicolumn{5}{|l|}{ Entertainment } \\
\hline MMR & $.15^{\star *}$ & -.06 & $.38^{\star *}$ & $.39^{* *}$ \\
\hline B-MMR & $.13^{\star *}$ & -.03 & $.32^{\star *}$ & $.38^{\star *}$ \\
\hline \multicolumn{5}{|l|}{ Revival } \\
\hline MMR & $.16^{\star *}$ & -.01 & $.53^{\star *}$ & $.45^{\star *}$ \\
\hline B-MMR & $.13^{\star *}$ & -.03 & $.47^{\star *}$ & $.45^{\star *}$ \\
\hline \multicolumn{5}{|l|}{ Strong Sensation } \\
\hline MMR & $.15^{\star *}$ & $-.15^{\star *}$ & $.63^{* *}$ & $.36^{* *}$ \\
\hline B-MMR & $.13^{\star *}$ & $-.13^{\star *}$ & $.61^{\star *}$ & $.36^{\star *}$ \\
\hline \multicolumn{5}{|l|}{ Diversion } \\
\hline MMR & $.25^{\star *}$ & .06 & $.42^{\star *}$ & $.28^{\star *}$ \\
\hline B-MMR & $.25^{\star *}$ & .01 & $.45^{\star *}$ & $.32^{\star *}$ \\
\hline \multicolumn{5}{|l|}{ Discharge } \\
\hline MMR & .07 & .02 & $.33^{* *}$ & $.33^{* *}$ \\
\hline B-MMR & .06 & .01 & $.32^{\star *}$ & $.31^{\star *}$ \\
\hline \multicolumn{5}{|l|}{ Mental Work } \\
\hline MMR & $.22^{\star *}$ & -.06 & $.54^{\star \star}$ & $.30^{\star *}$ \\
\hline B-MMR & $.19^{\star *}$ & -.03 & $.52^{\star \star}$ & $.30^{\star *}$ \\
\hline \multicolumn{5}{|l|}{ Solace } \\
\hline MMR & $.19^{* *}$ & -.02 & $.55^{\star \star}$ & $.34^{\star *}$ \\
\hline B-MMR & $.19^{\star *}$ & .00 & $.51^{\star *}$ & $.31^{\star *}$ \\
\hline \multicolumn{5}{|c|}{ MMR (total score) } \\
\hline MMR & $.22^{\star *}$ & -.04 & $.62^{\star *}$ & $.45^{\star *}$ \\
\hline B-MMR & $.20^{\star *}$ & -.03 & $.60^{\star *}$ & $.46^{\star *}$ \\
\hline
\end{tabular}

the daily amount of listening were Revival and Entertainment.

As additional information, age, and gender differences in B-MMR were explored. Age did not show any correlation to any of the B-MMR strategies. However, age has been found to relate to MMR in the earlier study (Saarikallio, 2008), in which MMR mean score was higher for 15-20-year-olds (3.42) than for 10- to 13-year-olds (3.06). Actually, the mean score of those 15- to 20-yearolds was close to the B-MMR mean score (3.48) of the current sample (mean age 23.97), preliminarily suggesting that mood-regulation through music increases during the teenage years but stabilizes during young adulthood. Regarding gender, men did not differ from women, except for Revival, which was slightly more used by men, $t(308)=2.29, p \leq .05$. This also contradicts the results of the previous study, which showed higher MMR scores for girls than for boys (Saarikallio, 2008). This may, however, again relate to age, as the earlier study showed significant interaction between gender and age, indicating earlier increase of MMR scores in girls than in boys.

\section{Discussion}

The current study resulted in a new brief version of the Music in Mood Regulation scale (B-MMR), and provided initial evidence for the scale's reliability and validity. The resulting 21-item scale is a theoretically coherent and easily administered self-report measure for assessing mood regulation through music, and may prove to be a highly applicable tool for further inquiries. The scale not only assesses the general tendency of using music as a means for mood regulation, but also differentiates between seven regulatory strategies referring to slightly different behavioral patterns regarding music use. Regarding the factor structure, other strategies appear 
separate, but Diversion and Mental work include some items that also load moderately on some other subfactors, implying that these strategies may be most reflective of the overall concept of music-related mood regulation.

The B-MMR correlated expectedly with general emotion regulation (ERQ). All MMR strategies except for Discharge correlated positively with reappraisal, confirming that B-MMR relates to an antecedent-focused cognitive processing of emotions, while no positive correlations were found for suppression. These correlations validate the expected general nature of B-MMR. Furthermore, some variation between the B-MMR strategies was observed. As the only response-focused strategy, Discharge - in line with the expectations - did not correlate with Reappraisal. Discharge could be considered similar to venting, expressive disclosure of negative affect (e.g., Tice \& Bratlawsky, 2000), but rather than verbal venting, Discharge more likely resembles the so-called modulated emotion expression, a process of first directing anger into a harmless activity (in this case music), and then redirecting the modulated anger to constructive activity such as self-assertion or negotiation (Izard, 2002). Indeed, Discharge did not correlate with suppression, which has previously been shown to correlate with venting (Gross \& John, 2003). Originally, none of the B-MMR strategies were expected to correlate with suppression, but a negative correlation of Strong Sensation to suppression was observed. Strong Sensation refers to "putting ones soul into music," capturing a tendency of merging oneself emotionally with the music, which is in line with previous research showing that music provides access to one's emotions (e.g., Sloboda, 1992). In retrospect, this tendency indeed can be considered being opposite to suppressing one's emotions. Thus, the current study validated the general nature of B-MMR, but future research could further clarify more detailed strategy-specific connections to different general emotion regulation strategies.

Regarding musical engagement, B-MMR correlated expectedly with both the self-perceived importance of music and the amount of music listening. This confirmed previous expectations about engaged music listeners using music for emotion-regulatory purposes more than non-engaged listeners (Greasley \& Lamont, 2011). Indeed, personal engagement with music may be a highly relevant aspect in understanding individual differences in the use of music for mood regulation: according to the current results, B-MMR correlated more strongly with musical engagement than general emotion regulation, which is further in line with earlier research stressing that while general emotion regulation relates to MMR, not all people who generally favor certain regulatory strategies may engage in a musical behavior for realizing them (Saarikallio, 2008). Regarding the type of musical behavior, B-MMR focuses on listening, and the positive correlations to the amount of listening support this. However, other musical behaviors such as composing, playing, singing, or dancing may also serve as relevant means for realizing at least some regulatory strategies, and this aspect should be addressed in more detail by future research.

Regarding the generalizability of B-MMR, the scale is originally designed for young people, and the two samples of the current study consisted of adolescents and young adults. However, since previous research has shown that the general nature of music-related mood regulation, including the range of different regulatory strategies, remains relatively similar across the adulthood years (Saarikallio, 2011), the B-MMR can be expected to be applicable for older age groups as well. The agerelated results from the current samples preliminarily indicate an increase of music-related mood regulation during adolescence while differences during young adulthood appear smaller.

Concise, theoretically well-grounded, and valid measurement instruments are a necessity for comparative and experimental investigations. Music-related mood regulation is a common behavior in people's everyday life, and music research should further examine how it relates to factors such as age, personality, musical background and music training, music-related emotion induction mechanisms, music preferences, or wellbeing and health outcomes. The current paper adds a small but significant step to the methodological development in the field by introducing a brief but comprehensive instrument for measuring the behavior.

\section{Author Note}

The current study was funded by the Academy of Finland (project 118616).

Correspondence concerning this article should be addressed to Suvi Saarikallio, Department of Music, P.O. Box 35, FIN-40014 University of Jyväskylä, Finland. E-MAIL: suvi.saarikallio@jyu.fi 


\section{References}

Catanzaro, S. J., \& Mearns, J. (1990). Measuring generalized expectancies for negative mood regulation: Initial scale development and implications, Journal of Personality Assessment, 50, 546-563.

DeNora, T. (1999). Music as a technology of the self. Poetics: Journal of Empirical Research on Literature, the Media, and the Arts, 26, 1-26.

DeNora, T. (2001). Aesthetic agency and musical practice: New directions in the sociology of music and emotion. In P. N. Juslin \& J. A. Sloboda (Eds.), Music and emotion: Theory and research (pp. 161-180). New York: Oxford University Press.

Greasley, A. E., \& LAMONT, A. (2011). Exploring engagement with music in everyday life using experience sampling methodology. Musicae Scientiae 15, 45-71.

Gross, J. J. (1998). The emerging field of emotion regulation: An integrative review. Review of General Psychology, 2, 271-299

Gross, J. J., \& John, O. P. (2003). Individual differences in two emotion regulation processes: Implications for affect, relationships, and well-being. Journal of Personality and Social Psychology, 85, 348-362.

IZARD, C. E. (2002). Translating emotion theory and research into preventive interventions. Psychological Bulletin, 128, 796-824.

JUSLIN, P. N., \& VÄSTFJÄLL, D. (2008). Emotional responses to music: The need to consider underlying mechanisms. Behavioral and Brain Sciences, 31, 559-621.

Kenny, D. T., \& Faunce, G. (2004). The impact of group singing on mood, coping and perceived pain in chronic pain patients attending a multidisciplinary pain clinic. Journal of Music Therapy, 16, 241-258.

LARSEN, R. J. (2000). Toward a science of mood regulation. Psychological Inquiry, 11, 129-141.

Parkinson, B., Toterdell, P., Briner, R. B., \& Reynolds, S. (1996). Changing moods: The psychology of mood and mood regulation. New York: Addison Wesley Longman Publishing Company.

Pelletier, C. L. (2004). The effect of music on decreasing arousal due to stress: A meta-analysis. Journal of Music Therapy, 16, 192-214.
SaArikallio, S. (2006). Differences in adolescents' use of music in mood regulation. In M. Baroni, A. R. Addessi, R. Caterina, \& M. Costa (Eds.), Proceedings of the 9th International Conference on Music Perception and Cognition. Bologna: Alma Mater Studiorum University of Bologna, Bologna.

SAARIKALLIO, S. (2008). Music in mood regulation: Initial scale development. Musicae Scientiae, 12, 291-309.

SAARIKALlio, S. (2011). Music as emotional self-regulation throughout adulthood. Psychology of Music, 39, 307-332.

SAARIKAllio, S., \& ERKKILÄ, J. (2007). The role of music in adolescents' mood regulation. Psychology of Music, 35, 88-109.

Salovey, P., Bedell, B. T., Detweiler, J. B., \& Mayer, J. D. (2000). Current directions in emotional intelligence research. In M. Lewis \& J. M. Haviland-Jones (Eds.), Handbook of emotions. New York: Guilford Press.

SLOBODA, J. A. (1992). Empirical studies of emotional response to music. In M. R. Jones \& S. Holleran (Eds.), Cognitive bases of musical communication. Washington, DC: American Psychological Association.

SlobodA, J. A., \& O’NeILL, S. A. (2001). Emotions in everyday listening to music. In P. N. Juslin \& J.A. Sloboda (Eds.). Music and emotion: Theory and research (pp. 415-429). New York: Oxford University Press.

Särkämö, T., Tervaniemi, M., Laitinen, S., Forsblom, A., SoINILA, S., MikKOnEN, M., ET AL. (2008). Music listening enhances cognitive recovery and mood after middle cerebral artery stroke. Brain, 131, 866-876.

Thayer, R. E., Newman, J. R., \& McClain, T. M. (1994). Selfregulation of mood: Strategies for changing a bad mood, raising energy, and reducing tension. Journal of Personality and Social Psychology, 67, 910-925.

TiCE, D. M., \& BRATLAWSKY, E. (2000). Giving in to feel good: The place of emotion regulation in the context of general self-control. Psychological Inquiry, 11, 149-159.

Van Goethem, A. (2009, August/September). The functions of music for affect regulation. Paper presented at the $1^{\text {st }}$ International Conference on Music and Emotion, Durham, UK. 
APPENDIX A: Factor loadings, $R^{2}$ values, error residuals, and cross-loadings of all items of the original 40-item MMR scale. Items selected for the Brief MMR are in bold, while removed items are not in bold.

\begin{tabular}{|c|c|c|c|c|}
\hline Item statements & $\begin{array}{l}\text { Factor } \\
\text { loading }\end{array}$ & $R^{2}$ & $\begin{array}{l}\text { Standardized } \\
\text { error }\end{array}$ & $\begin{array}{l}\text { Cross-loadings } \\
\text { over } .30^{*}\end{array}$ \\
\hline \multicolumn{5}{|l|}{ Entertainment (E) } \\
\hline $\begin{array}{l}\text { I usually put background music on to make the atmosphere } \\
\text { more pleasant }\end{array}$ & .77 & .59 & .41 & \\
\hline $\begin{array}{l}\text { When I'm busy around the house and no one else is around, } \\
\text { I like to have some music on the background }\end{array}$ & .69 & .51 & .53 & \\
\hline $\begin{array}{l}\text { I listen to music to make cleaning and doing other housework } \\
\text { more pleasant }\end{array}$ & .63 & .40 & .61 & \\
\hline When I'm going out (for example for school, hobbies, or a party), & .63 & .40 & .60 & \\
\hline
\end{tabular}

I listen to music to get myself in the right mood

\section{Revival (R)}

I listen to music to perk up after a rough day

.75

When I'm exhausted, I listen to music to perk up

When I'm tired out, I rest by listening to music

Listening to music helps me to relax

When I'm exhausted, I get new energy from music

I listen to music to get a breathing space in the middle of a busy day

Listening to music doesn't help me to relax

Strong Sensation (SS)

Music has offered me magnificent experiences

I want to feel the music in my whole body

I feel fantastic putting my soul fully into the music

Music offers me unforgettable moments (26)

Music does not evoke strong emotional experiences in me

I want to listen to music that evokes feelings in me

Sometimes music feels so great that I get goose bumps (in a positive sense)

Diversion (Div)

For me, music is a way to forget about my worries

When stressful thoughts keep going round and round in my head, I start to listen to music to get them off my mind

When I feel bad, I try to get myself in a better mood by engaging in some nice, music-related activity

Listening to music helps to block out disturbing factors from my mind

I can't push my worries aside with the help of music

Discharge (Dis)

When I'm really angry, I feel like listening to some aggressive music

When everything feels bad, it helps me to listen to music that expresses my bad feelings

When I'm angry with someone, I listen to music that expresses my anger

When I get angry, I give vent to my anger by listening to music that expresses my anger

When everything feels miserable, I start to listen to music that expresses these feelings

When I'm angry, I almost never listen to aggressive music

$\begin{array}{lll}.75 & .57 & .44\end{array}$

$\begin{array}{lll}.72 & .53 & .48\end{array}$

$\begin{array}{lll}.71 & .53 & .50\end{array}$

$\begin{array}{lll}.72 & .52 & .48\end{array}$

$\begin{array}{lll}.73 & .54 & .46\end{array}$

$\begin{array}{lll}.60 & .37 & .64\end{array}$

$\begin{array}{lll}-.45 & .21 & .80\end{array}$

$\begin{array}{lll}.73 & .54 & .46\end{array}$

$\begin{array}{lll}.72 & .53 & .48\end{array}$

$\begin{array}{lll}.71 & .52 & .50\end{array}$

$\begin{array}{lll}.74 & .54 & .46\end{array}$

$\begin{array}{lll}-.53 & .28 & .72\end{array}$

$\begin{array}{lll}.69 & .48 & .52\end{array}$

$\begin{array}{lll}.68 & .46 & .54\end{array}$

(2)

44
48
50
48
46
.64
80
46
48
50
46
72
52
54

\begin{tabular}{|c|c|c|c|}
\hline .75 & .62 & .43 & $\begin{array}{c}-.32 \text { on } S S \\
.32 \text { on } S\end{array}$ \\
\hline .68 & .51 & .54 & $\begin{array}{l}.56 \text { on } R \\
-.62 \text { on } M W \\
-.41 \text { on } S\end{array}$ \\
\hline .67 & .44 & .56 & $\begin{array}{l}.52 \text { on } \mathrm{MW} \\
.54 \text { on } \mathrm{S}\end{array}$ \\
\hline .58 & .34 & .67 & -.42 on $\mathrm{S}$ \\
\hline-.51 & .26 & .74 & -.34 on $\mathrm{S}$ \\
\hline .85 & .72 & .29 & \\
\hline .64 & .71 & .29 & \\
\hline .81 & .65 & .35 & \\
\hline .77 & .60 & .40 & \\
\hline .80 & .65 & .35 & \\
\hline-.72 & .51 & .49 & \\
\hline
\end{tabular}


APPENDIX A: Continued.

\begin{tabular}{|c|c|c|c|c|}
\hline Item statements & $\begin{array}{l}\text { Factor } \\
\text { loading }\end{array}$ & $\boldsymbol{R}^{2}$ & $\begin{array}{c}\text { Standardized } \\
\text { error }\end{array}$ & $\begin{array}{l}\text { Cross-loadings } \\
\quad \text { over } .30^{\star}\end{array}$ \\
\hline \multicolumn{5}{|l|}{ Mental Work (MW) } \\
\hline Music helps me to recognize different feelings in myself & .76 & .63 & .43 & -.59 on Div \\
\hline Music has helped me to get through hard experiences & .79 & .60 & .38 & \\
\hline $\begin{array}{l}\text { When I'm distressed by something, music helps me to clarify } \\
\text { my feelings }\end{array}$ & .79 & .56 & .38 & $\begin{array}{l}.42 \text { on Div } \\
.72 \mathrm{~S}\end{array}$ \\
\hline $\begin{array}{l}\text { Listening to music takes me back and gets me thinking about } \\
\text { different things that have happened to me }\end{array}$ & .62 & .38 & .62 & $\begin{array}{l}.43 \text { on SS } \\
-.53 \text { on Div }\end{array}$ \\
\hline Music inspires me to think about important issues & .68 & .46 & .54 & -.43 on Div \\
\hline \multicolumn{5}{|l|}{ Solace (S) } \\
\hline When everything feels bad, music understands and comforts me & .84 & .70 & .30 & \\
\hline When I'm feeling sad, listening to music comforts me & .83 & .70 & .31 & \\
\hline I listen to music to find solace when worries overwhelm me & .82 & .67 & .33 & \\
\hline When something is troubling me, I find solace in music & .82 & .67 & .33 & \\
\hline Listening to music doesn't comfort me in my sorrows & -.63 & .39 & .61 & \\
\hline Music is like a friend who understands my worries & .79 & .62 & .38 & \\
\hline
\end{tabular}

${ }^{*}$ Relevant cross-loadings were only found for Diversion and Mental Work. Overall, more than two thirds of the cross-loadings were as low as below 0.10.

\section{Appendix B}

\section{B-MMR}

The Brief Music in Mood Regulation scale (B-MMR) includes three item statements for each regulatory strategy. Items are answered on 5-point Likert-scale ranging from "Strongly Disagree" to "Strongly Agree."

\section{ENTERTAINMENT: HAPPY MOOD MAINTENANCE}

1. I usually put background music on to make the atmosphere more pleasant

2. When I'm busy around the house and no one else is around, I like to have some music on the background

3. I listen to music to make cleaning and doing other housework more pleasant

\section{REVIVAL: RELAXATION AND NEW ENERGY}

1. I listen to music to perk up after a rough day

2. When I'm exhausted, I listen to music to perk up

3. When I'm tired out, I rest by listening to music

STRONG SENSATION: INTENSE EMOTION INDUCTION

1. Music has offered me magnificent experiences

2. I want to feel the music in my whole body

3. I feel fantastic putting my soul fully into the music

DIVERSION: DISTRACTION FROM WORRIES AND STRESS

1. For me, music is a way to forget about my worries
2. When stressful thoughts keep going round and round in my head, I start to listen to music to get them off my mind

3. When I feel bad, I try to get myself in a better mood by engaging in some nice, music-related activity

DISCHARGE: RELEASE AND VENTING OF NEGATIVE EMOTION

1. When I'm really angry, I feel like listening to some angry music

2. When everything feels bad, it helps me to listen to music that expresses my bad feelings

3. When I'm angry with someone, I listen to music that expresses my anger

MENTAL WORK: CONTEMPLATION AND REAPPRAISAL OF EMOTIONAL EXPERIENCE

1. Music helps me to understand different feelings in myself

2. Music has helped me to work through hard experiences

3. When I'm distressed by something, music helps me to clarify my feelings

SOLACE: EMOTIONAL VALIDATION AND SUPPORT WHEN

FEELING DOWN

1. When everything feels bad, music understands and comforts me

2. When I'm feeling sad, listening to music comforts me

3. I listen to music to find solace when worries overwhelm me 